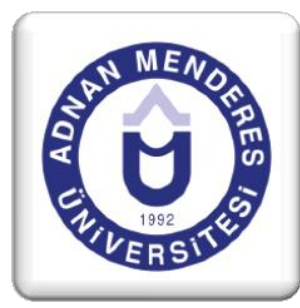

\title{
Otel Çalışanlarının Bilgi Paylaşımı Tutum Düzeyleri: 4 Yıldızlı Bir Otelin Odalar Bölümünde Uygulama
}

\section{Hotel Employees' Attitudes About Information Sharing: Application in a 4-star Hotel's Room Department}

\author{
Sine ERDOĞAN MORÇİN ${ }^{1}$, ,llhami MORÇìN ${ }^{2}$
}

\section{Özet}

Bilgi çağı olarak adlandırılan günümüz dünyasında, bilginin sağlanması, paylaşılması ve yönetilmesi bütün işletmeler için olduğu gibi turizm işletmeleri için de önemlidir. Özellikle, turizm sektöründeki işletmelerin yüksek tempolu çalışma düzeni düşünüldügünde bilginin (mesleki, tecrübeye dayalı ve pratik) işletmenin bir değeri haline getirilmesinin hızlı çözümler sağlayabileceği söylenebilir. Bilgi yönetimi faaliyetleri içinde, bilgi paylaşımı konusu önemli bir yere sahiptir. Günümüz işletmelerinin bilgi paylaşımı konusundaki en önemli amaçları ise çalışanların örtük bilgilerini açığa çıkarmak ve bu bilgileri işletmenin bir değeri haline getirebilmektir. Bu amaca ulaşabilmek için, çalışanların bilgi paylaşımı hakkındaki tutumlarının bilinmesinin yöneticilere pratik yarar sağlayabileceği söylenebilir. Dolayısıyla, otel çalışanlarının bilgi paylaşımı konusundaki tutumlarının araştırıldığı bu çalışmanın, otel yöneticilerinin bilgi yönetimi faaliyetlerine katkı sağlaması beklenmektedir. Bu araştırmada, uygulama alanı olarak, Antalya bölgesinde faaliyet gösteren 110 odalı ve 4 yıldızlı bir otel işletmesinin odalar bölümü seçilmiştir. Araştırmanın evreni 43 kişiden oluşmaktadır. Veriler 42 kişinin anket sorularına verdikleri cevaplardan elde edilmiş ve SPSS'te analiz edilmiştir. Sonuçta, çalışanların bilgi paylaşımı konusunda en yüksek tutumu, bilgi paylaşımının önündeki bireysel engeller boyutunda gösterdikleri ortaya çıkmıştır.

Anahtar Kelimeler: Bilgi Paylaşımı, Otel İşletmesi, Odalar Bölümü

\footnotetext{
* Bu çalışmanın ilk hali, VII. Lisansüstü Turizm Öğrencileri Kongresi'nde sunulmuştur, Erdoğan Morçin ve Morçin, 2014.

${ }^{1}$ Öğr. Gör., Ardahan Üniversitesi, Çıldır MYO, Turizm ve Otel İşletmeciliği Programı, semorcin@ardahan.edu.tr

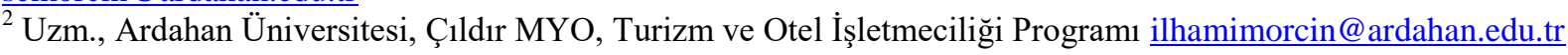




\begin{abstract}
In today's world of so-called information age, information provision, shared and managed as it is for all businesses is also important for tourism businesses. In particular, considering the high-paced working order of businesses in the tourism sector, knowledge (professional, based on experience and practice) into a value of the business provide solutions quickly can be said. Knowledge sharing issues have an important place in knowledge management activities. The most important of goal today's enterprise in sharing knowledge is to uncover employees' implicit informatio, and this information is to make the business value. To achieve this goal, knowledge of employee attitudes about sharing information can provide practical benefits to managers can be said. Therefore, in this study that the hotel employees' attitudes about information sharing investigated expected to contribute to the hotel managers's knowledge management activities In this study, as the application area, room division of 110 rooms and 4-star business hotel operating in the region Antalya is selected. Research population is composed of 43 people. Data were obtained 42 people of their answers to the questionnaire and analyzed in SPSS. As a result, the highest attitude of employees sharing information have emerged in the dimension of individual blocks on the front of sharing information.
\end{abstract}

Keywords: Knowledge Sharing, Hotel Business, Rooms Division

\title{
1. Giriş
}

Günümüzde bilgi giderek artan bir öneme sahiptir. Bilgi ile ilgili yapılan araştırmalar, özellikle bilginin işletmeler için yaşamsal bir unsur olduğu konusuna vurgu yapmaktadırlar. Çünkü işletmelerin değeri haline getirilebilen bilgiler, taklit edilmesi kolay olmadığı için işletmelere önemli rekabet avantajı sağlamaktadır. Bilginin, işletmenin bir değeri haline getirebilmek için öncelikle onun paylaşımının sağlanması gerekmektedir. Bu sebeple literatürde bilgi paylaşımı konusunun, bilgi yönetimi faaliyetleri içinde önemli bir yere sahip olduğu vurgulanmaktadır. $\mathrm{Bu}$ bağlamda yöneticilerin, çalışanların bilgi paylaşımı tutumlarının bilmesinin işletmelere önemli avantajlar sağlayacağı söylenebilir.

Otel işletmeleri bilindiği üzere emek yoğun işletmeler olarak kabul edilmektedirler. Dolayısıyla işlerin yapılmasındaki hız kadar bilginin aktarılmasındaki hızın da önemli olduğu söylenebilir. Çünkü bilgi paylaşımını hızı, işlerin yapımını da etkileyecektir. Örneğin tecrübeli bir kat görevlisinin yatak yapımının püf noktalarını yeni işe başlayan bir personele öğretmeye gönüllü olması hem emek hem de zaman tasarrufu sağlayabilecektir. Buna ek olarak, bir resepsiyonistin müşteriyi oda ile ilgili bir konuda ikna etme aşamasında izlenecek stratejileri yeni işe başlayan çalışana aktarmaya gönüllü olması da aynı avantajları sağlayabilir. Bu araştırma, Antalya'da bulunan 4 yıldızlı bir otel 
işletmesinin odalar bölümünü uygulama alanı olarak ele almıştır. Otel işletmesi araştırma boyunca "A Oteli” olarak isimlendirilmiştir. A Oteli'nin odalar bölümünde, departman yöneticileri dahil 43 kişi çalışmaktadır. Bunların 11'i önbüro departmanında, 32'si ise kat hizmetleri departmanında görev yapmaktadır. Veriler 42 kişiye yüz yüze uygulanan anketler aracılığıyla toplanmış ve SPSS ile analiz edilmiştir. Tek bir otel işletmesinin odalar bölümünün ele alınmış olması araştırmanın en önemli kısıtıdır. Dolayısıyla, sonuçlar yalnızca A Oteli’nin odalar bölümü için genellenebilir bir niteliğe sahiptir.

\section{Kuramsal Çerçeve}

Literatürde yapılan tanımlar incelendiğinde bilgi tanımlarında daha çok 'akıl' unsuruna; örgütsel bilgi tanımlarında ise daha çok 'tecrübe ve çalışma' unsurlarına vurgu yapıldığı görülmektedir. Bununla birlikte, bilgi paylaşımı konusuna daha çok örgütsel bilgi tanımlarında vurgu yapıldı̆̆ı görülmektedir. Türkçe literatürde 'bilgi', 'veri' ve 'enformasyon' terimleri sıklıkla birbirlerinin yerine kullanılmaktadır. Halbuki veri ve enformasyon kavramları yakın ilişkili olmakla beraber, farklı anlamlar taşıyan kavramlardır (Yılmaz, 2009: 100). Ancak bu üç kavram her ne kadar birbirlerinden farklı anlamlara gelseler de, tanımlarını yapabilmek için birbirlerine ihtiyaç duyulmaktadır. Aktaş (1987) veriyi 'temel gerçekler ve düşünceler; enformasyonu 'değerlendirme yapılırken kullanılacak belge, rapor vb. nesneler'; bilgiyi ise karar alırken kullanılan enformasyon ve bundan çıkarılan sonuçlar olarak tanımlamıştır (Medeni ve Aktaş, t.y: 2; Celep ve Çetin, 2003).

Bilgi kavramı, Latince 'informatio' kökünden olup, biçim verme, biçimlendirme ve haber verme eylemi olarak tanımlanmaktadır (Şimşek ve Çelik, 2011: 374). Nonaka'ya (1994) göre ise 'bilgi doğru inançların açıklanmasıdır'. Literatürde yer alan diğer bazı bilgi tanımları Çizelge 1'de gösterilmiştir.

Çizelge 1. Bilgi/Örgütsel Bilgi Tanımları

\begin{tabular}{|c|c|c|c|}
\hline \multicolumn{2}{|c|}{ BİLGí } & \multicolumn{2}{|c|}{ ÖRGÜTSEL BİLGİ } \\
\hline Yazar & Tanım & Yazar & Tanım \\
\hline Polanyi (1996) & $\begin{array}{l}\text { 'Bilgi, insanların etkin } \\
\text { yaratım ve kendi } \\
\text { deneyimlerini örgütlü } \\
\text { hale getirmeleri } \\
\text { neticesinde ortaya } \\
\text { çıan değerdir'. }\end{array}$ & $\begin{array}{l}\text { Grayson ve O'dell } \\
\text { (1998) }\end{array}$ & $\begin{array}{l}\text { 'Örgütsel bilgi, } \\
\text { insanların müşteriler, } \\
\text { ürünler, süreçler, } \\
\text { yanlışlar ve başarılar } \\
\text { hakkında bildikleridir'. }\end{array}$ \\
\hline Beijerse (1999) & $\begin{array}{l}\text { 'Bilgi, temel olarak } \\
\text { insanların } \\
\text { yaşamlarındaki } \\
\text { belirsizliği azaltma } \\
\text { gereksinimidir'. }\end{array}$ & $\begin{array}{l}\text { Bollinger ve Smith } \\
(2001)\end{array}$ & $\begin{array}{l}\text { 'Örgütsel bilgi, zaman } \\
\text { içinde yoğunlaşan ve } \\
\text { örgüttün sezgisine } \\
\text { doğru ilerleyen derin } \\
\text { düzeyde bir algıdır'. }\end{array}$ \\
\hline $\begin{array}{l}\text { Hackbortu ve Gruber } \\
\text { (1999) }\end{array}$ & $\begin{array}{lr}\text { 'Bilgi, veri } & \text { veya } \\
\text { enformasyondan } & \text { daha } \\
\text { üst düzey } & \text { bir } \\
\text { kavramdır'. } & \end{array}$ & Gharize (2004) & $\begin{array}{l}\text { 'Örgütsel bilgi, çalışma } \\
\text { veya tecrübe yoluyla } \\
\text { kazanılmış anlayıştır' }\end{array}$ \\
\hline
\end{tabular}




\begin{tabular}{|l|l|l|l|}
\hline Makaras (1999) & $\begin{array}{l}\text { 'Bilgi, akıl tarafından } \\
\text { üretilen bir anlamdır'. }\end{array}$ & Argote (2005) & $\begin{array}{l}\text { 'Örgütsel bilgi, örgütün } \\
\text { kayitlarında, } \\
\text { kurallarında, } \\
\text { standartlarında veya } \\
\end{array}$ \\
& & $\begin{array}{l}\text { çalışanların } \\
\text { tecrübelerinde, ve } \\
\text { kişisel yeteneklerinde } \\
\text { sakli olan bilgidir'. }\end{array}$ \\
\hline
\end{tabular}

Kaynak: Celep ve Çetin, 2003; Güçlü ve Sotırofski, 2006; Yılmaz, 2011'den uyarlanmıştır.

Bilginin türü bilgi yönetimi faaliyetlerini etkileyen önemli bir unsurdur. Literatürde bilgi, 'açık' ve 'örtük' bilgi olarak değerlendirilmektedir (Uzun ve Durna, 2008: 34). Bu ayrım ilk olarak Michael Polanyi (1966) tarafından ele alınmasına karşın, bu ayrımı yapmanın önemi Nonaka ve Takeuchi aracılığıyla vurgulanmıştır (Mısırdalı, 2006: 14). Açık bilgi, dökümante edilebilen, arşivlenen ve kodlanan her türlü bilgiyi içermektedir (Kulaklı, 2005: 100). Nonaka, örtük bilgiyi açık bilgiye dönüştürmek için metaforların sözcüklere aktarılması gerektiğini belirtmiştir (Kothari et al. 2012: 3). Örtük bilgi, kişisel, formüle edilmesi zor, uygulandıkça ve denendikçe öğrenilen bilgidir (Kulakl1, 2005: 100). Örtük bilginin dışa yansıyabilmesi için üst düzey bir paylaşım ortamı sağlanmalı ve yüz yüze iletişimi sağlayan etkin bir iletişim ortamı hazırlanmalıdır (Doğan, 2004a: 6). Bu sayede, bireysel düzeydeki bilgi önce grupsal düzeye, sonra örgütsel düzeye ulaşabilecek ve işletmenin bir değeri haline gelebilecektir (Sağsan, 2002: 22). Örtük bilginin dişa vurumu sayesinde, işletmeler stratejik bir rekabet avantajı sağlayabilirler (Doğan, 2004b: 8). Çünkü bilgi yönetimi uygulamaları, rekabete direnen ve yaptığı işlerden verim elde etmek isteyen örgütler için vazgeçilmez yönetim metotlarından biridir (Odabaş, 2003: 360). Bu bağlamda, bir bilgi yönetimi uygulaması olarak örtük bilginin açı̆̆a çıkarılmasının turizm işletmelerine stratejik bir rekabet avantajı sağlayacağı söylenebilir.

Bilgi yönetiminin temel taşları, bilgi toplama, bilgi üretimi, bilgi depolama ve bilgi paylaşımıdır (Çetinkaya, 2012: 55). Bilgi paylaşımı ise bireysel veya örgütsel amaçları gerçekleştirmek ve başarıyı artırmak için birey ile birey, örgüt ile örgüt ve birey ile örgüt arasında bilginin değişimi ve kabulü olarak tanımlanmaktadır (Davenport ve Prusak, 2001: 26-27). Bilgi paylaşımı için gerekli ortamı üst yönetim oluşturmalıdır. Üst düzey yöneticiler, örgüt üyelerinin davranışları için değerler geliştirmeli ve bilgi paylaşımı konusundaki tutumlarını olumlu yönde geliştirmek için çeşitli stratejiler izlemelidirler (Celep ve Çetin, 2003: 107; İnce, 2005: 331). Bu konuda en önemli unsur ise, yöneticinin bilgi paylaşımını destekleyici ve gerçekleşmesine zemin hazırlayan bir örgüt kültürünü oluşturmuş olmasıdır (Nemli, 2007: 97). Diğer önemli bir husus ise bilgi liderliğidir. Bilgi liderliği, verimliliğin artması, çalışanlarla bilgi paylaşımının kolaylaşması, yeteneklerin daha çok geliştirilmesi, olumlu bir ortamın sağlanması ve küresel süreçlerdeki firsatların karlılığa dönüştürülmesini sağlamaktadır (Karahan, 2009).

Vatansever Toylan ve Semerciöz (2013: 737) özellikle örgüt içi paylaşımını etkileyen unsurların örgütlerarası güven, (ortaklardan) öğrenme niyeti, iletişim, (ortağın) özümseme kapasitesi, paylaşılan vizyon ve bağl1lık olduğunu belirtmişlerdir. Çavuşluoğlu (2010: 114), turizm işletmelerinin hizmet ve diğer işletmeler ile bilgi paylaşımı temelinde çalıştıklarını belirterek, karlılıklarını, verimliliklerini, müşteri memnuniyeti ve pazarlama performanslarını artırabilmeleri için, bilişim teknolojileri destekli iş yapma modellerinden maksimum düzeyde faydalanmaları gerektiğini belirtmiştir. Bahar (2011: 60-61) ise, konaklama işletmelerinin bilgi yönetimi alt yapılarını incelediği çalışmasında, konaklama işletmelerinde bilgi paylaşımı için gerekli olan teknolojik alt yapının yeterli olduğunu ortaya koymuştur. Ancak yazar, öğrenme odaklı insan kaynakları politikası belirlenmesi, formel ve informel iletişim kanallarının artırılması ve örgütsel yapıda düzenlemeye gidilmesi gerektiği 
konularına vurgu yapmıştır. Sarı ve Kozak (2005: 372), yaptıkları çalışmalarında, seyahat acentelerinin müşterilerle bilgi paylaşımını güçlendirmek için web sitesine sahip olmayı, konaklama işletmelerine göre daha çok önemsediklerini ortaya koymuşlardır. Dönmez (2008: 116), seyahat acenteleri ile otel işletmeleri arasındaki bilgi paylaşımının arttıkça otel işletmelerinin performanslarının arttığını ortaya koymuştur. Geçikli vd., (2011:180), otel işletmelerinde departmanlar ve personeller arası bilgi paylaşımının sağlanabilmesi için örgütsel iletişsimin iyi bir araç olduğunu belirtmişlerdir.

Yukarıda verilen bilgiler ve önceki literatür 1şığında, turizm sektöründe faaliyet gösteren işletmelerin üst düzey yöneticilerinin, çalışanların bilgi paylaşımı tutumlarının ne düzeyde olduğunu bilip, bu düzeye göre stratejiler geliştirmelerinin ve bilgi liderliği yapmalarının önemli avantajlar sağlayacağı söylenebilir. Örneğin tecrübeye dayalı teknik bilgi, yeni işe başlayan personele hızla aktarılabilir. Diğer taraftan, turizm işletmeleri çalışanlarının bilgi paylaşımı tutumlarını olumlu yönde geliştirmeye çalışmazlarsa, çalışanın sahip olduğu tecrübeye dayalı bilginin ortaya çıkarılamayacağı ve çalışanın zihninde örtük bir bilgi olarak kalacağı söylenebilir.

\section{Yöntem}

Bu çalışmada, 'odalar bölümü çalışanlarının bilgi paylaşımı tutumları hangi düzeydedir?' sorusuna cevap aranmıştır. Literatürde, bilgi paylaşımı tutumu konusunu otel işletmelerinin bölümleri bazında ele alan yeterli sayıda araştırma ile karşılaşılmadığı için, araştırmanın turizm sektörü açısından önemli bir boşluğu doldurabileceği düşünülmektedir. $\mathrm{Bu}$ nedenle araştırmanın önemli olduğu söylenebilir. Araştırma betimsel tarama türündedir. Uygulama alanı olarak Antalya'da faaliyet gösteren 110 odalı ve 4 y1ldızlı bir otel seçilmiştir. Bu otelin seçilmesinin nedeni yöneticilerin odalar bölümü çalışanlarıyla yüz yüze görüşme yapılmasına imkan sağlamalarıdır. Araştırma verilerinin, düşük sezon olarak nitelendirilen Kasım ayında toplanmasının da, yöneticilerin araştırmaya yönelik tutumlarını olumlu etkilediği düşünülmektedir. A Oteli'nin odalar bölümünde yöneticiler dahil toplam 43 kişi çalışmaktadır. Bunların 11'i önbüro bölümünde, 32'si ise kat hizmetleri bölümünde çalışmaktadır. Dolayısıyla odalar bölümü ve araştırma evreni toplam 43 kişiden oluşmaktadır. Evren sınırlı olduğu için, örneklem alınmamış ve tam sayım yapılması hedeflenmiştir. Ancak 1 kişi araştırmaya katılmak istememiştir. Bu nedenle 42 anket elde edilebilmiştir. Buna göre anket geri dönüş oranı \%98'dir. Araştırmaya ilişkin ölçek Chow, Deng ve Ho (2000) tarafından geliştirilen ve Öztürk (2005) tarafından Türkiye'de iletişim sektöründe uygulanan 28 önermeden oluşan bir ölçektir. Daha önce Türkiye'deki işletmelerde kullanıldığı için geçerlilik doğrulayıcı faktör analizi ile sınanmıştır. Ölçeğin güvenirlik katsayısı 0,745 olarak hesaplanmıştır. Buna göre ölçeğin oldukça güvenilir olduğu söylenebilir. Ayrıca 6 demografik soru içeren ölçek de ankette yer almaktadır.

\section{Bulgular}

Bulgular bölümünde demografik bulgulara ve tutum ölçeklerinden elde edilen ortalama puanlara yer verilmiştir. Tablo 1'de araştırmanın demografik bulgularına yer verilmiştir. Tablo 1'de görüldügü üzere çalışmaya katılan cevaplayanların çoğu kadınlardan 26-40 yaş arasında olanlardan, evlilerden, lise mezunlarından ve 1-5 yıldır mevcut otelde çalışmakta olan odalar bölümü çalışanlarından oluşmaktadır. Aşağıdaki tablolarda odalar bölümü çalışanlarının bilgi paylaşımına yönelik tutumları değerlendirilmiştir. Araştırmada kullanılan ölçek toplam 28 ifadeden ve 4 boyuttan 
oluşmaktadır. Verilen yanıtların bu boyutlara göre ortalamaları, çalışanların tutumlarının hangi boyutta daha yüksek düzeyde, hangi boyutta daha düşük düzeyde olduğunu ortaya koyacaktır.

Tablo 1. Demografik Özellikler

\begin{tabular}{|c|c|c|c|}
\hline \multirow{3}{*}{ Cinsiyet } & Tür & $\mathbf{N}$ & $\%$ \\
\hline & Kadın & 33 & 78,6 \\
\hline & Erkek & 9 & 21,4 \\
\hline \multirow[b]{3}{*}{ Yaş } & $18-25$ & 19 & 45,2 \\
\hline & $26-40$ & 21 & 50,0 \\
\hline & $41-55$ & 2 & 4,8 \\
\hline \multirow{2}{*}{ Medeni Durum } & Bekar & 11 & 26,2 \\
\hline & Evli & 31 & 73,8 \\
\hline \multirow{5}{*}{ Eğitim Durumu } & İlkokul & 4 & 9,5 \\
\hline & Ortaokul & 12 & 28,6 \\
\hline & Lise & 14 & 33,3 \\
\hline & Önlisans & 9 & 21,4 \\
\hline & Lisans & 3 & 7,1 \\
\hline \multirow{4}{*}{$\begin{array}{l}\text { Mevcut Oteldeki } \\
\text { Tecrübeleri }\end{array}$} & 1 y1ldan az & 15 & 35,7 \\
\hline & $1-5$ & 25 & 59,5 \\
\hline & $6-10$ & 2 & 4,8 \\
\hline & Toplam & 42 & 100 \\
\hline
\end{tabular}

Tablo 2 incelendiğinde ölçeklerin KMO ve Barlett test sonuçlarının faktör analizi yapmak için uygun olduğu görülmektedir. Bununla birlikte ölçeklerin tamamının açıklanan varyansı \%50'nin üstündedir. Yapılan doğrulayıcı faktör analizi sonucunda ölçeklerin tamamının tek faktör yapısı doğrulanmıştır. Buna göre sonuçların geçerli olduğu söylenebilir.

Tablo 2. Doğrulayıcı Faktör Analizi Sonuçları

\begin{tabular}{|l|c|c|c|}
\hline Ölçek & İfade Sayısı & $\begin{array}{c}\text { KMO/Barlett } \\
\text { Test }\end{array}$ & $\begin{array}{c}\text { Açıklanan } \\
\text { Varyans }\end{array}$ \\
\hline Bilgiye Bakış Açısı & 7 &, $819 /, 000$ & $\% 79,117$ \\
\hline Bilgi Paylaşımı Algısı & 7 &, $634 /, 000$ & $\% 69,752$ \\
\hline Örgüt içi Bilişsel Kanalların Açıklı̆̆1 & 8 &, $645 /, 000$ & $\% 73,623$ \\
\hline Bilgi Paylaşımının Önündeki Bireysel Engeller & 6 &, $539 /, 000$ & $\% 79,284$ \\
\hline
\end{tabular}

Tablo 3'te çalışanların bilgiye bakış açıları boyutunu oluşturulan ifadelere yer verilmiştir. $\mathrm{Bu}$ ifadelere verilen yanıtların ortalaması 3,19 'dur. $\mathrm{Bu}$, yüksek bir ortalama olarak değerlendirilebilir. 
Tablo 3. Çalışanların Bilgiye Bakış Açıları Boyutu

\begin{tabular}{|c|c|c|c|}
\hline İFADELER & $\mathbf{N}$ & $\begin{array}{c}\text { S. } \\
\text { Hata }\end{array}$ & $\overline{\mathbf{X}}$ \\
\hline 1.Sahip olduğum bilgi, benim için güç kaynağıdır & \multirow{7}{*}{42} & \multirow{7}{*}{1,08} & \multirow{7}{*}{3,19} \\
\hline 2.Sahip olduğum bilgi, bana özeldir, paylaşmak zorunda değilim & & & \\
\hline 3.Sahip olduğum bilgiler işletme için önemli bir değerdir. & & & \\
\hline $\begin{array}{l}\text { 4.Otelim sayesinde kazandığım bilgiler bana özel değildir, otelin } \\
\text { bir değeridir. }\end{array}$ & & & \\
\hline $\begin{array}{l}\text { 5.Sahip olduğum bilgiler pozisyonumu korumamam yardım } \\
\text { ediyor. }\end{array}$ & & & \\
\hline 6.Bilgi paylaşımı işletme içinde bana avantaj sağlar. & & & \\
\hline $\begin{array}{l}\text { 7.Otel içindeki bireylerin birbirini iyi tanıması bilgi paylaşımını } \\
\text { kolaylaştırır. }\end{array}$ & & & \\
\hline
\end{tabular}

Tablo 3'te çalışanların bilgiye bakış açıları boyutunu oluşturulan ifadelere yer verilmiştir. $\mathrm{Bu}$ ifadelere verilen yanıtların ortalamas 1,19 'dur. $\mathrm{Bu}$, yüksek bir ortalama olarak değerlendirilebilir.

Tablo 4. Çalışanların Bilgi Paylaşımına Yönelik Algılamaları

\begin{tabular}{|c|c|c|c|}
\hline İFADELER & $\mathbf{N}$ & $\begin{array}{c}\text { S. } \\
\text { Hata }\end{array}$ & $\overline{\mathbf{X}}$ \\
\hline 8.Yeni bir teknik geliștirdiğimde, iş arkadaşlarımla paylaşırım & \multirow{7}{*}{42} & \multirow{7}{*}{0,56} & \multirow{7}{*}{3,00} \\
\hline 9.Yeni bir teknik geliştirdiğimde, yöneticilerimle paylaşırım & & & \\
\hline 10.İş arkadaşlarımla işle ilgili paylaşımda bulunurum & & & \\
\hline 11.Yöneticiler çalışanlardan gelen fikirlerle ilgilenirler & & & \\
\hline 12.Bilgi paylaşımında ödüllendirme benim için bir belirleyicidir & & & \\
\hline 13.Hiyerarşik yapı bilgi paylaşımını güçleştirir & & & \\
\hline 14.Bilgi kişiye özel olsa da paylaşılmalıdır & & & \\
\hline
\end{tabular}

Tablo 4'te çalışanların bilgi paylaşımına yönelik algılamaları boyutunu oluşturulan ifadelere yer verilmiştir. $\mathrm{Bu}$ ifadelere verilen yanıtların ortalaması 3,00 'tür. $\mathrm{Bu}$, yüksek bir ortalama olarak değerlendirilebilir.

Tablo 5. Bilgi Paylaşımında Örgüt İçi Bilişsel Kanalların Açıklığı

\begin{tabular}{|c|c|c|c|}
\hline İFADELER & $\mathbf{N}$ & $\begin{array}{c}\text { S. } \\
\text { Hata }\end{array}$ & $\overline{\mathbf{X}}$ \\
\hline 15.Otelimizde, hatalarımızdan ders çıkarırız & \multirow{8}{*}{42} & \multirow{8}{*}{0,74} & \multirow{8}{*}{3,16} \\
\hline 16.Takım çalışmasıyla her türlü bilgiyi paylaşırız & & & \\
\hline 17.Otelimizde çalıșanlar her zaman üst yönetime ulaşabilir. & & & \\
\hline 18.Otelimizde çalışanların konuşabilecekleri alanlar vardır & & & \\
\hline $\begin{array}{l}\text { 19.Otelimizde düzenli olarak çalışanlar için sosyal aktiviteler } \\
\text { düzenlenir }\end{array}$ & & & \\
\hline $\begin{array}{l}\text { 20.Otelimizde parasal ödül, ayın personeli gibi onursal teşvikler } \\
\text { yapılır }\end{array}$ & & & \\
\hline $\begin{array}{l}\text { 21.Otelimizde yöneticiler hatalarının ortaya çıkmasından } \\
\text { korkmazlar }\end{array}$ & & & \\
\hline 22.Yöneticilerimiz başarıları kadar başarısızlıklarını da açıklar & & & \\
\hline
\end{tabular}

Tablo 5'te bilgi paylaşımında örgüt içi bilişsel kanalların açıklı̆̆ boyutunu oluşturulan ifadelere yer verilmiştir. Bu ifadelere verilen yanıtların ortalaması 3,16'dır. Bu, yüksek bir ortalama olarak değerlendirilebilir. 
Tablo 6. Bilgi Paylaşımının Önündeki Bireysel Engeller

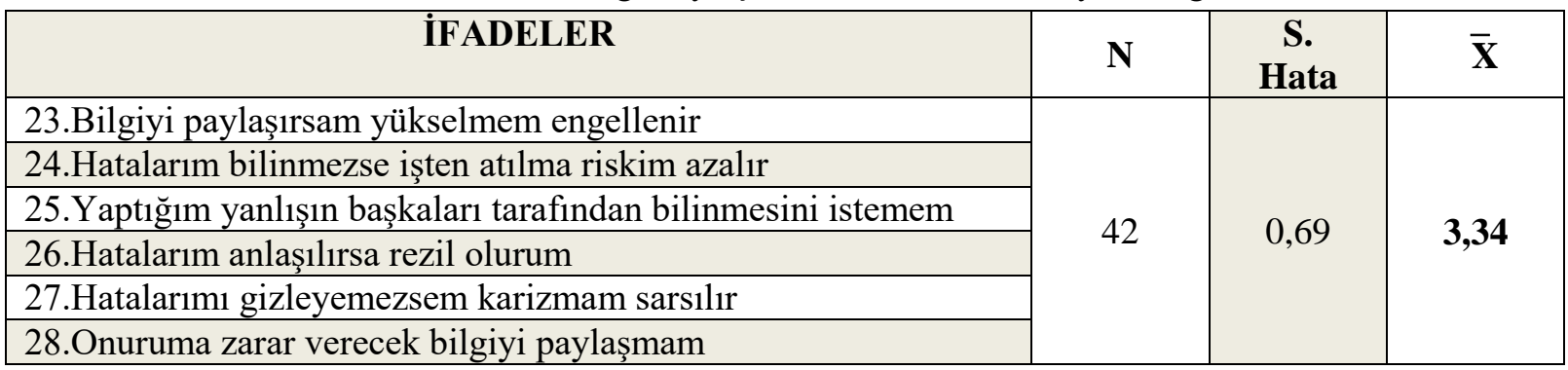

Tablo 6'da bilgi paylaşımının önündeki bireysel engeller boyutunu oluşturulan ifadelere yer verilmiştir. $\mathrm{Bu}$ ifadelere verilen yanıtların ortalaması 3,34'tür. Bu, yüksek bir ortalama olarak değerlendirilebilir.

\section{Sonuç}

Bilgi, bilginin kullanılması ve yönetimi, bilgi paylaşımı ve bilginin işletmenin değeri haline getirilmesi zamanla yarışan otel işletmeleri için de son derece önemli bir konudur. Ancak literatürde otel işletmelerinin bölümlerine yönelik bilgi paylaşımı araştırmalarının yeterli olmadığ gözlenmiştir. $\mathrm{Bu}$ çalışma 'odalar bölümü çalışanlarının bilgi paylaşımı tutumları ne düzeydedir?' sorusuna cevap aramak için yapılmıştır. Antalya'daki A oteli odalar bölümü çalışanlarının verdiği cevaplar doğrultusunda en yüksek tutum ortalamasının ( $\bar{X}=3,34)$ bilgi paylaşımının önündeki bireysel engeller boyutunda ortaya çıktığı görülmüştür. Buna göre, A oteli odalar bölümü çalışanlarının bilgi paylaşımından, hatalarının ortaya çıkması, yükselmelerinin engellenmesi ve işten atılabilecekleri düşüncesi ile paylaşmaktan kaçındıkları söylenebilir. Íkinci en yüksek ortalama $(\overline{\mathbf{X}}=3,19)$ değerine sahip boyut çalışanların bilgiye bakış açıları boyutudur. Buna göre, A oteli odalar bölümü çalışanlarının bilgiyi başarılarının kaynağı olarak gördükleri, bilginin kendilerine işletme içinde avantaj sağladığını düşündükleri ve bilgiyi işletmenin bir değeri olarak gördükleri söylenebilir. Buna göre A oteli odalar bölümü çalışanlarının bilginin ve onun sağladığı gücün bilincinde oldukları

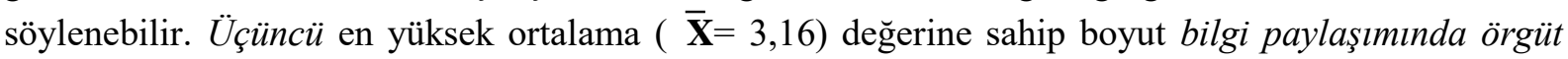
içi bilişsel kanalların açıklı̆̆ boyutudur. Buna göre, A oteli odalar bölümü çalışanlarının otellerinde bilginin paylaşılmasına zemin hazırlayan alanların var olduğunu ve bilgiyi istedikleri zaman üst yönetime iletebilecekleri düşüncesine sahip oldukları söylenebilir. Diğer boyutlara göre en düşük ( $\overline{\mathbf{X}}=3,00$ ) ortalama çalışanların bilgi paylaşımına yönelik algılamaları boyutunda ortaya çıkmıştır. Diğer boyutlara göre değerlendirildiğinde A oteli odalar bölümü çalışanlarının, yeni ürettikleri bir teknik ve ya bilgiyi daha az paylaşma tutumu gösterdikleri söylenebilir. Sonuç olarak, en yüksek ortalama değere sahip boyutun bilgi paylaşımının önündeki bireysel engeller boyutunun alması, bize bilgi paylaşımı tutumunu etkileyen bireysel faktörler hakkında önemli ipuçları vermektedir. Buna göre yöneticilerin Tablo 5'te açık ifadeler ile belirtilen engelleri değerlendirerek çözüm stratejileri geliştirmeleri önerilebilir. 


\section{KAYNAKÇA}

Bahar, E. (2011). 'Konaklama İşletmelerinde Bilgi Yönetimi: A ltyapı, Uygulama ve Karşılaşılan Engeller', İsletme Araştırmaları Dergisi, 3 (2), 51-68.

Celep, C. Ve Çetin, B. (2003) Bilgi Yönetimi. Ankara: Anı Yayınları.

Chow, C. W.; Deng, F. J. ve Ho, J. L. (2000) 'The openness of knowledge sharing within organizations: A comparative study in the United States and the People's Republic of China', Journal of Management Accounting Research; Vol.:12, ss.65-95.

Çavuşoğlu, M. (2010). 'Konaklama İşletmelerinde Elektronik Ticaret Kullanımı: Gökçeada ve Bozcaada'da Bir Araştırma', Girişimcilik ve Kalkınma Dergisi, 5 (2), 111-141.

Çetinkaya, A. (2012). 'Örgütsel Bilgi Yönetim Sürecinde Bilgi Yönetim Performansı Boyutları: Ölçek Geliştirme ve Geçerliliği Üzerine Bir Araştırma', Online Academic Journal Of Information Technology, 3 (9), DOI: 10.5824/1309-1581.2012.4.004.x, http://www.ajite.org/?menu=pages $\& p=$ details of article $\&$ id $=53$, (Erişim Tarihi: 11.01 .2014$)$.

Davenport, T. ve Prusak, L. (2001) İş Dünyasında Bilgi Yönetimi. İstanbul: Rota Yayınları.

Doğan, H. (2004a). 'Bilgi Teknolojileri Örtülü Bilgi İçin Bir Fırsat Mı? Tehdit Mi? Bilgi Teknolojilerinin Örtülü Bilgi Bağlamlı Kullanım Stratejileri’, Gazi Üniversitesi Ticaret Turizm Ë̆itim Fakültesi Dergisi, 1, 97-107.

Doğan, H. (2004b). 'Kültürel Bir Miras Olan Örtülü Bilginin Sosyolojik ve Stratejik Analizi ve Bunun Uluslararas1 Pazarlara Yansitılma Stratejileri’, Gazi Üniversitesi Ticaret Turizm Eğitim Fakültesi Dergisi, 1, 84-96.

Dönmez, D. (2008). 'Paydaş Teorisi Çerçevesinde Otel İşletmelerinin Seyahat Acenteleri İle İlişkileri ve Otel İşletmelerinin Performansı Arasındaki İlişkiye Yönelik Bir Araştırma’, Yönetim, 19 (61), 91-112.

Geçikli, F.; Serçeoğlu, N.; Üst, Ç. (2011). 'Örgüt İçi İletişim ve İletişim Tatmini Konaklama İşletmelerinde Bir Uygulama’ İletişim Kuram ve Araştırma Dergisi, Güz, Sayı: 33, 163-184.

Güçlü, N. Ve Sotırofski, K. "Bilgi Yönetimi", Türk Eğitim Bilimleri Dergisi, 4(4), 351-371.

İnce, M. (2005). 'Değişim Olgusu ve Örgütlerde İnsan Kaynakları Yönetiminin Değişen Fonksiyonları', Selçuk Üniversitesi Sosyal Bilimler Enstitüsü Dergisi, 14, 319-339.

Karahan, A. (2009). 'Bilgi Liderliğinin Verimlilik Üzerine Etkisi: Sağlık Sektöründe Bir Araştırma', Bilgi Dünyas1, 10 (1), 60-79.

Kothari, A.; Rudman, D.; Dobbins, M.; Rouse, M.; Sibbald, S.; Edwards, N. (2012). 'The Use Of Tacit And Explicit Knowledge In Public Health: A Qualitative Study' Implemantation Science, 7:20, http://www.implementationscience.com/content/pdf/1748-5908-7-20.pdf (Erişim Tarihi: 02.01.2014). 
Kulaklı, A. (2005). 'Yeni Ürün Geliştirme Sürecinde Bilgi Paylaşımının Önemi Ve Bir Uygulama', İstanbul Ticaret Üniversitesi Fen Bilimleri Dergisi, 4 (8), 99-114.

Medeni, T.İ; Aktaş, Z. (t.y). 'Veri Toplumundan Bilgi Toplumuna Dört Düzeyli Bir Toplum Modeli', http://www.emo.org.tr/ekler/fdac58e60abb571_ek.pdf (Erişim Tarihi: 11.01.2014).

Mısırdalı, F. (2006). Örgüt Iç̧i Bilgi Paylaşımında Sosyal Sermayenin Etkisi: Kütahya Porselen A.Ş'de Bir Uygulama. Yüksek Lisans Tezi, Kütahya: Dumlupınar Üniversitesi Sosyal Bilimler Enstitüsü.

Nemli, H. (2007). Örgüt Kültürü İle Bilgi Paylaşımına Yönelik Bir Araştırma. Yüksek Lisans Tezi, Kütahya: Dumlupınar Üniversitesi Sosyal Bilimler Enstitüsü.

Nonaka, I. (1994).'A Dynamic Theory of Organizational Knowledge

Creation', Organization Science, 5(1), 14- 37.

Odabaş, H. (2003). 'Kurumsal Bilgi Yönetimi’. Türk Kütüphaneciliği, 17 (4), 357-368.

Öztürk, A. (2005) Isşletmelerde Bilgi Yönetimi ve Bilgi Paylaşımı: Eskişehir Türk Telekom'da Örnek Bir Uygulama. Yüksek Lisans Tezi, Kütahya: Dumlupınar Üniversitesi Sosyal Bilimler Enstitüsü.

Sarı, Y.; Kozak, M. (2005). 'Turizm İşletmelerinde Doğrudan Pazarlama Çabaları Kapsamında Bilgi Teknolojilerinin Kullanımı', Iktisadi ve Ídari Bilimler Dergisi, 19 (1), 359-383.

Sağsan, M. (2002). 'Örgütsel Seçimlerde Küme Modeli: İnsan İlişkileri, Bilgi Yönetimi ve Örgütsel Öğrenmenin Ara Kesitinde ‘İnsan', http://eprints.rclis.org/7349/1/205-230.pdf (Erişim Tarihi: $02.01 .2014)$

Şimşek, M.Ş. ve Çelik, A. (2011) Yönetim ve Organizasyon. Konya: Eğitim Akademi.

Uzun, H.; Durna, U. (2008). 'İşletmelerde Rekabet Unsuru Olarak Bilgi Yönetimi', Niğde Üniversitesi, İktisadi Ve İdari Bilimler Fakültesi Dergisi, 1 (1), 33-40.

Vatansever Toylan, N.; Semerciöz, F. (2013). 'Stratejik İttifak Oluşumundaki Konaklama Sektöründe İşletmeler Arası İlişkileri Düzenleyici Faktörler ve Bir Model Önerisi', International Conference On Eurasian Economies, St.Petersburg-Russia, 734-743, http://www.eecon.info/papers/741.pdf (Erişim Tarihi: 19.09.2014).

Yılmaz, B. (2009). 'Gerçekliğin Toplumsal İnşasında Bilgi ve Bilgi Merkezi', Bilgi Dünyası, 10 (1), 23-34.

Yılmaz, M. (2011). ‘Bilgi Yönetimi ve Örgütsel Öğrenme İlişkisi: Kavramsal Bir Yaklaşım', Atatürk Üniversitesi Türkiyat Araştırmaları Enstitüsü Dergisi, 46, 313-332. 